\title{
Prevalência do uso de narguilé entre universitários da área da saúde
}

\author{
Prevalence of narguile use among university students in the health area
}

\author{
Michelle Oliveira Paiva ${ }^{1}$, André Brito de Lima ${ }^{1}$, Rogério Saad $\operatorname{Vaz}^{2}$, Priscila Granemann ${ }^{3}$
}

Paiva MO, Lima AB, Vaz RS, Granemann P. Prevalência do uso de narguilé entre universitários da área da saúde / Prevalence of narguile use among university students in the health área. Rev Med (São Paulo). 2020 jul.-ago.;99(4):335-41.

\begin{abstract}
RESUMO: Narguilé é a principal forma de uso do tabaco e ocupa a segunda posição no Brasil. Considerando esse cenário e a forma crescente de utilização, buscou-se identificar a prevalência, frequência e malefícios do uso de narguilé entre os estudantes da área da saúde ${ }^{10}$. Trata-se de um estudo descritivo exploratório com abordagem quantitativa, visando conhecer a realidade dos estudantes universitários dos cursos de biomedicina, medicina e enfermagem de uma instituição filantrópica de Curitiba ${ }^{11} .39$ $(33,8 \%)$ referiram tabagistas, com utilização regular, $92,8 \%$ afirmaram realizar uso do narguilé, sendo que $59 \%$ utilizou pela primeira vez entre 13 e 16 anos. $61,5 \%$ acredita que o cachimbo d'água não causa danos quando comparado ao cigarro e 89,75\% nunca foram aconselhados a abandar o vício. Em suma, a alta prevalência relevante de tabagismo e utilização de narguilé reitera a importância de ações de enfretamento, a fim de maximizar a prevenção e combate ao tabagismo.
\end{abstract}

Descritores: Saúde pública; Produtos do tabaco; Fumar; Cachimbos de água; Tabagismo.

\begin{abstract}
Narghile is the main form of smoking in many countries and occupies the second position in Brazil. Considering this scenario, and this growing form of smoking, we aimed to identify the prevalence of water tobacco pipe, frequency and harm use among health students ${ }^{10}$. This is an exploratory-descriptive study with a quantitative approach, aiming to know the reality of biomedical, medical, nursing undergraduate students from a philanthropic institution from Curitiba ${ }^{11}$. Of the total sample, 39 (33.8\%) referred using some form of cigarette smoke, with some regularity, considering occasional smokers, $92.8 \%$ reported using narghile, $59 \%$ used for the first time between 13 and 16 years of age. $61.5 \%$ believe that narghile does not cause diseases like cigarettes and $89.75 \%$ have never been advised to stop smoking. As a conclusion, the high prevalence of smoking and the use of narguile reiterates the actions in order to maximize the prevention and combat against smoking.
\end{abstract}

Keywords: Public health; Tabacco products; Smoking; Smoking water pipes; Tobbaco use disorder.

1. Estudante de Medicina, Faculdades Pequeno Príncipe, Curitiba, PR, Brasil. ORCID: Paiva MO - https://orcid.org/0000-0002-4231912X; Lima AB - https://orcid.org/0000-0002-8819-2830. Email: michelle_mop@ymail.com, andrebrito2015@gmail.com.

2. Professor Doutor pela Universidade Federal do Paraná, Faculdades Pequeno Príncipe. ORCID: https://orcid.org/0000-0002-75375320. Email: rogerio.vaz@fpp.edu.br.

3. Mestranda PECS-FPP - Curitiba, PR, Brasil. ORCID: https://orcid.org/0000-0002-8448-2240. Email: priigranemann@gmail.com. Endereço para correspondência: Michelle Oliveira Paiva. Rua Coronel Amazonas Marcondes, 933 - Cabral. Curitiba, PR. CEP: 800-35.230. 


\section{INTRODUÇÃO}

$\mathrm{O}$ cachimbo d'água, conhecido popularmente como narguilé, é uma forma de uso tradicional do tabaco que começou a ser utilizado há muitos séculos na antiga Pérsia e na Índia como forma de consumir o ópio. Inclusive foi na forma de narguilé que o tabaco foi introduzido na China durante a dinastia Ming, no século $16^{1}$.

De acordo com a Pesquisa Mundial do uso de Tabaco na Juventude ${ }^{2}$, a prevalência do uso de narguilé no Oriente Médio ultrapassa o consumo de cigarro convencional, 6-34\% entre os adolescentes e 5-17\% entre os jovens americanos. O seu uso vem se popularizando cada vez mais pela Europa e Américas, especialmente entre os jovens, se colocando como a segunda forma mais consumida de tabaco nos Estados Unidos, França, Reino Unido e Brasil.

O narguilé é composto pelo fornilho, corpo, vaso de água e bocal. Os furos no fundo do fornilho permitem que a fumaça passe no canal central do corpo que é submerso em água, passa então pelo tabaco que, ao ser aquecido, produz a fumaça. A fumaça passa pelo corpo do narguilé, borbulha na água do vaso e é carregada pela mangueira até o fumante ${ }^{3}$.

Em um estudo realizado, em 2011, com estudantes da área da saúde no Brasil, 55\% declaravam fazer uso de narguilé ${ }^{2}$. Devido a esse aumento crescente de consumidores nos últimos anos, em 2012 a campanha do Dia Nacional do Combate ao Fumo o tema escolhido pelo Ministério da Saúde foi: "Alerta para os malefícios do narguilé". E o que faz com que os jovens se interessem cada vez mais por essa droga? A resposta é simples: inserção e aceitação pelo meio.

$\mathrm{Na}$ busca por requisitos que façam com que o jovem se insira em um grupo ou tenha "afinidade" com um par, eles se predispõem à dependência química da nicotina precocemente. Além de ser um meio de aceitação, os odores e sabores variados do produto exercem uma atração, que mascara os efeitos irritantes da fumaça.

Devido a exposição do tabaco a altas temperaturas, pela queima de carvão, uma sessão de narguilé (60 minutos) equivale a um consumo médio de 119 litros de fumaça, o que corresponde a 4 vezes mais nicotina, 60-100 vezes mais alcatrão e 15 vezes mais monóxido de carbono quando comparado ao cigarro tradicional. Essas elevadas concentrações de monóxido de carbono podem causar intoxicação, o que gera um quadro de dor de cabeça, tontura, náuseas, fraqueza e síncope ${ }^{4}$.

Akl et al. ${ }^{9}$ realizaram uma revisão sistemática de 24 estudos sobre os efeitos do uso de narguilé na saúde. "Descobriu-se que o uso de narguilé é significativamente associado com câncer de pulmão (OR = 2,12; IC95\%: 1,32-3,42) e doenças respiratórias $(O R=2,3$; IC95\%: 1,1$5,1)$ " (p.2). Além das complicações anteriores, uma única sessão de fumo (45 minutos) causa disfunção transitória da regulação cardíaca autonômica, o que eleva os riscos de eventos cardíacos.

O conhecimento errôneo de que o narguilé cause menos malefícios sobre a saúde quando comparado ao cigarro, gera diversos impasses à comunidade de controle do tabagismo, pois aumenta a necessidade de intervenção desses órgãos sobre a conscientização dos riscos aos quais os fumantes estão expostos. É relevante lembrar também da importância do papel dos profissionais da saúde na abordagem e repasse de informações aos pacientes usuários.

Nesse sentido, para a atual pesquisa polemiza a seguinte questão: Qual a prevalência, frequência e malefícios do uso de narguilé entre os universitários da área da saúde em uma Faculdade de Ensino Superior de Curitiba?

\section{MÉTODO}

Trata-se de um estudo descritivo com abordagem quantitativa ${ }^{5}$. Conforme Roesch ${ }^{10}$, "o enfoque da quantitativa é utilizar a melhor estratégia de controlar o delineamento da pesquisa para garantir uma boa interpretação dos resultados" (p.50). Através da abordagem quantitativa, consegue-se com analise de técnicas estatísticas, quantificar opiniões e informações. Associado ao estudo descritivoexploratório, foi possível descrever as características de uma população, o que permite uma maior familiaridade entre pesquisador e tema pesquisado.

A pesquisa foi realizada em Instituição de Ensino Superior, da área da saúde, de Curitiba. Através da análise dos dados, colhidos mediante Questionário sobre Uso de Narguilé entre Estudantes da Área da Saúde (adaptado através do Questionário sobre Tabagismo FURG 199 e Ministério da Saúde, a amostra da pesquisam, escolhida aleatoriamente, era inicialmente composta por 150 estudantes, no entanto a pesquisa foi realizada efetivamente com 106 estudantes da área da saúde, sendo 39 estudantes do curso de Medicina ( $8^{\circ}$ período), 32 de Biomedicina ( $3^{\circ} \mathrm{e}$ $6^{\circ}$ períodos $)$ e 35 de Enfermagem $\left(2^{\circ}\right.$ e $4^{\circ}$ períodos $)$ de uma faculdade da área da saúde de Curitiba. A perda amostral deveu-se a questionários não respondidas adequadamente e presença de informações inconsistentes. Conforme Barbetta $^{11}$, a amostragem é utilizada nas pesquisas cientificas em que se quer conhecer uma característica da população, "é comum observar-se apenas uma amostra de seus elementos, e a partir dos resultados dessa amostra, obter valores aproximados, ou estimados para as características populacionais de interesse" (p.41). 
A coleta de dados aconteceu em setembro de 2018, por meio de questionário constituído de questões semiestruturadas, contendo as seguintes abordagens: sexo, idade, etnia, condição relacionada ao fumo, o que fuma, com que idade começou a fumar, quantos anos fuma, associação com outras drogas, frequência de fumo, conhecimento sobre os malefícios, fuma dentro de casa, como começou a fumar e em que ocasiões costuma fumar. Sendo assim, as informações foram coletadas no intervalo das atividades curriculares de uma Instituição de Ensino Superior da Área da Saúde, dos cursos de Medicina, Biomedicina e Enfermagem, sob supervisão de um docente da faculdade e com o consentimento dos participantes.

A análise dos dados foi realizada através da junção de respostas coletadas por meio do questionário semiestruturado. Foram separadas “opiniões” semelhantes e realizado cálculo de frequência simples das respostas obtidas para cada pergunta do questionário. Com os percentuais determinados, foram realizadas a interpretação dos dados. Dessa forma, a organização e a análise dos dados foram realizadas de acordo com as seguintes etapas de construção: determinação dos objetivos da pesquisa, seleção dos pontos que serão levantados, elaboração do instrumento de coleta, seleção da amostra que será pesquisada, junção das informações coletadas, interpretação e análise dos dados com métodos estatísticos, que foram calculados através de frequência simples, e por fim, a apresentação dos resultados de forma descritiva.

Os critérios de inclusão selecionaram estudantes que aceitaram participar do trabalho, maiores de 18 anos e que assinaram o termo de consentimento livre e esclarecido (TCLE). Como critérios de exclusão inclui-se estudantes universitários menores de 18 anos ou que não aceitaram assinar o TCLE.

Desta forma, a presente pesquisa respeitou os preceitos firmados na Resolução 466/12 do Conselho Nacional de Saúde, os princípios éticos estabelecidos se comprometem a zelar pela legitimidade das informações, sigilo e privacidade das informações. $O$ trabalho foi aprovado pelo Comitê de Ética e Pesquisa, número
2.865 .655 .

\section{RESULTADOS}

Participaram da pesquisa 106 estudantes dos cursos de biomedicina, enfermagem e medicina. Sendo 35 alunos $(33 \%)$ do $2^{\circ}$ e $4^{\mathrm{a}}$ períodos do curso de enfermagem, 32 alunos $(30,2)$ do $3^{\circ}$ e $6^{\circ}$ períodos de biomedicina e 39 alunos $(36,8 \%)$ do $8^{\circ}$ período do curso de medicina. Os períodos analisados foram escolhidos com o objetivo de comparar a prevalência do tabagismo no início da graduação, em relação a períodos superiores dos cursos da área da saúde.

Ao todo, 85,8\% foram mulheres e 14,2\% homens, sendo que essa proporção se deu pelo maior número de mulheres matriculadas nos cursos analisados. A idade mediana dos participantes ficou em 17,5 anos para as mulheres e 17 anos para homens, não havendo assim grande distinção de idade entre os sexos. Quanto à etnia, um maior número se autodeclararam branca, sendo $86,8 \%$ do total, outros $9,4 \%$ pardo e 3,8\% amarelo.

A prevalência de usuários foi de $33,8 \%$, sendo que desses, $31 \%$ se consideram fumantes ocasionais e apenas $2,8 \%$ fumantes. Um percentual de fumantes foi evidenciado entre os estudantes do curso de graduação de biomedicina, do total de alunos do curso, $43,75 \%$ se dizem fumantes ocasionais e 6,25\% fumantes. Destaca-se que dentre todos os acadêmicos fumantes que se dizem ocasionais, $72 \%$ responderam que fumam mensalmente e $26 \%$ semanalmente, além disso, o presente estudo também desvelou que dentre esses mesmos tabagistas, $64,1 \%$ o fazem através do uso somente do narguilé. 23,6\% usam tanto o cigarro como o narguilé e $5,1 \%$ disseram usar narguilé, cigarro e charuto, dessa forma evidenciou-se um número expressivamente menor em relação aos alunos que usam somente o cigarro convencional, que foi de $5,1 \%$ (Tabela 1). Desvelou-se alta prevalência de usuários do narguilé, totalizando $92,8 \%$ da amostra de fumantes e fumantes ocasionais, desses, $71,8 \%$ disseram que preferem fumar na presença de amigos e 2,6\% sozinhos, o que aponta uma relação entre socialização e uso do narguilé.

Tabela 1 - Percentual de consumo de produtos do tabaco (2019; IES de Curitiba; N = 106)

\begin{tabular}{cccccc}
\hline & Cigarro & Cigarro, e charuto & Narguilé & Cigarro e narguilé & Cigarro, narguilé e charuto \\
\hline$\%$ & 5,1 & 2,1 & 64,1 & 23,6 & 5,1 \\
\hline
\end{tabular}

Os usuários de narguilé também foram questionados sobre a idade que começaram a fumar e os resultados demonstraram que 59\% iniciaram na faixa etária entre 13 e 16 anos, $33 \%$ entre 17 e 20 anos e $8 \%$ entre 21 a 23 anos, com esses resultados obtém-se também um menor percentual de iniciação do tabagismo conforme o aumento da idade (Gráfico 1). Os resultados revelaram ainda que $20,5 \%$ da amostra dos que fazem uso de narguilé associam o tabaco a outras drogas, como a maconha, citado em mais de $50 \%$ dos casos e o álcool em 12\% (Gráfico 2). 
Gráfico 1 - Idade de início do tabagismo por faixa etária $(\mathrm{N}=106)$

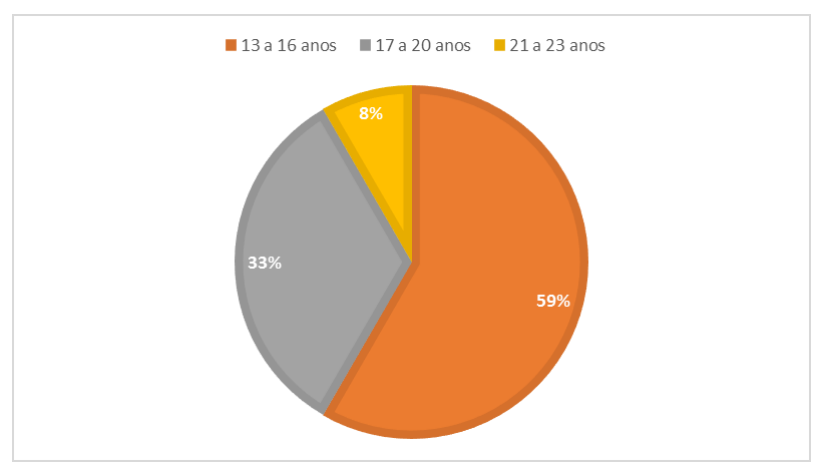

Gráfico 2 - Associações do narguilé com outras drogas $(\mathrm{N}=106)$

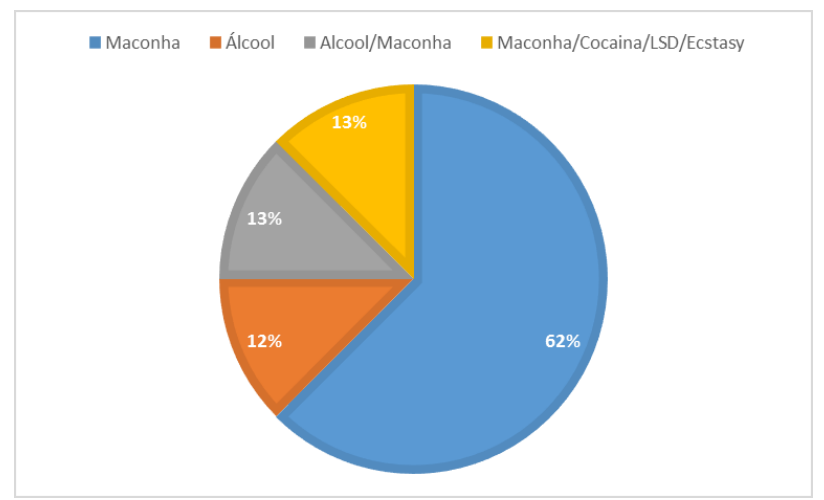

Em relação às percepções dos estudantes sobre malefícios do uso do narguilé, $61,5 \%$ referiram que o narguilé não faz mal e $38,5 \%$ responderam que faz mal. Desses $38,5 \%, 73,2 \%$ disseram que pode causar problemas no sistema respiratório, dentre eles foram citados: doença pulmonar obstrutiva crônica, enfisema pulmonar, câncer de pulmão, doenças das vias respiratórias, perda dos cílios nas vias respiratórias e falta de ar; 6,7\% responderam que os malefícios dependem da frequência de uso e $20 \%$ não souberam responder, apesar de assinalarem que o narguilé é maléfico a saúde (Tabela 2).

Tabela 2 - Percepções, hábitos, associações e aconselhamento sobre o tabagismo $(\mathrm{N}=106)$

\begin{tabular}{lcc}
\hline & Sim & Não \\
\hline $\begin{array}{l}\text { Narguilé faz mal? } \\
\begin{array}{l}\text { Conhecimentos em relação } \\
\text { aos malefícios }\end{array}\end{array}$ & $38,5 \%$ & $61,5 \%$ \\
\hline $\begin{array}{l}\text { Fuma dentro de casa? } \\
\begin{array}{l}\text { Aconselhado a parar de } \\
\text { fumar? }\end{array}\end{array}$ & $41 \%$ & $20 \%$ \\
\hline
\end{tabular}

\section{DISCUSSÃO}

O narguilé assume a segunda maior forma de consumo de tabaco em países como EUA, Reino Unido, França e Brasil ${ }^{3}$, e vem se popularizando cada vez mais, consagrando-se um padrão de status, assim como o consumo de charutos no século XX. A aceitação pelo meio, aromas e sabores atrativos, socialização, falsas crenças de que não há muitos malefícios à saúde e de que não causa dependência, são apontados em trabalhos recentes como importantes fatores que contribuem para o aumento de sua prevalência nos últimos anos; levando a aceitação do narguilé como uma opção mais segura de tabagismo em relação ao cigarro, principalmente entre os jovens. Ribeiro et al. ${ }^{1}$ coloca em um editorial essa discussão sobre a falsa crença por parte desses adolescentes remetendo à sua origem na índia, quando se sugeriu que a água do recipiente do narguilé, por onde a fumaça passa, filtraria as impurezas e assim seria menos prejudicial à saúde do fumante.

Frente ao combate ao tabagismo nos dias atuais, esses jovens acabam buscando outros meios de consumir o tabaco, e encontram no narguilé uma alternativa ${ }^{6}$. O presente estudo reforça o que foi descrito, e reitera através de percentuais, que mais da metade do total de entrevistados $(61,5 \%)$ acreditam que o narguilé é menos prejudicial quando comparado ao cigarro. Além disso grande parte da amostra analisada tem predileção pelo uso de narguilé (92,1\%). Uma razão possível para a ideia de consumo seguro do narguilé tida por parte desses jovens, é a de que o fazem com baixa frequência, amenizando assim os danos. Um material informativo sobre o narguilé, explica que os jovens tendem a não acreditar serem fumantes convencionais pela baixa frequência de uso e, desse modo, não se consideram dependentes do tabaco ${ }^{7}$.

No Brasil, de acordo com o Pesquisa Nacional de Saúde (2015, p. 1), “dentre os 212 mil usuários de narguilé no país, 112 mil (53\%) fumam esporadicamente, enquanto 27,5 mil (13\%) fazem uso uma vez por mês, 57,2 mil (27\%) semanalmente e 14,8 mil (7\%) afirmam realizar o consumo diariamente" (p.1). Proporção de usuários relacionados a frequência de consumo, também foram encontrados no presente estudo: $71,8 \%$ dos usuários fazem uso mensalmente, $25,6 \%$ utilizam uma vez na semana, enquanto $2,6 \%$ consomem o produto diariamente ${ }^{3}$.

Uma única sessão de narguilé, de aproximadamente uma hora, equivale a fumar em média 100 cigarros, o que significa fumar cinco carteiras, sendo o fumante exposto as mesmas substâncias toxicas do cigarro convencional. Ao retornarmos a frequência de uso encontrada na presente investigação, vê-se que quase o total de alunos (98\%), diz fumar mensalmente ou semanalmente. Destaca-se ainda que não há prova científica que demonstre meios seguros de consumo do tabaco. Essa informação parece ainda não estar totalmente clara, e esse entendimento pode ser reforçado se relacionarmos os dados obtido quando os alunos responderam que os malefícios dependiam da frequência de uso. No entanto, muitos associaram o uso de narguilé ao desenvolvimento de doenças pulmonares, fato que pode ser confirmado por um estudo realizado pelo Governo do Paraná. O trabalho relaciona o uso da droga ao 
aumento da probabilidade de desenvolver doenças como: pneumonia; câncer de pulmão, laringe, boca, estômago; infertilidade; dentre diversas outras ${ }^{8}$.

Além das doenças mencionadas, o uso compartilhado de mangueiras aumenta a ocorrência de doenças transmissíveis, dentre elas podemos citar: herpes, tuberculose, hepatite, gripe, inclusive $\mathrm{H} 1 \mathrm{~N} 1^{8}$.

Assim como outros produtos derivados do tabaco, o narguilé contém nicotina e as mesmas 4.700 substâncias tóxicas do cigarro convencional (alcatrão, hidrocarbonetos, carbonilas, fenóis, amônia, ácido cianídrico, metais pesados - chumbo, arsênio, níquel, mercúrio, nitrosaminas, aminas aromáticas, $\mathrm{NOx})^{7}$. No entanto, analises realizadas pela Sociedade de Pneumologia e Tisiologia do Rio de Janeiro, comprovam que a fumaça contém quantidades superiores de nicotina, monóxido de carbono, metais pesados e substâncias cancerígenas se comparadas ao cigarro. A nicotina, além de causar dependência, provoca vasoconstrição, taquicardia, elevação da pressão arterial e aumento o risco de aterosclerose; por isso os índices de alterações cardíacas são mais elevados entre os fumantes. O monóxido de carbono, realiza uma combinação estável e irreversível com a hemoglobina, reduzindo a capacidade de oxigenação dos tecidos, podendo causar alteração do nível de consciência, asfixia e morte. As outras substâncias químicas presente na composição da droga, tem o potencial de alterar genes (câncer), destruir os cílios presentes no sistema respiratório - o que facilita o contato frequente com infecções, provocar inflamação de brônquios (bronquite) e bronquíolos e destruição progressiva dos alvéolos pulmonares (enfisema), contribuindo para o quadro de dificuldade respiratória ${ }^{1,8}$.

Segundo a Organização Mundial da Saúde, "o tabagismo é a principal causa de morte evitável em todo o planeta. Seis milhões de pessoas morrem no mundo por ano devido ao uso do cigarro, e somente no Brasil, $75 \%$ dos fumantes começam a fumar antes dos 18 anos". Adolescentes fumantes possuem alta probabilidade de se tornarem adultos fumantes. Quanto mais cedo você se torna dependente do tabaco, maior o risco de desenvolver câncer e outras doenças crônicas não transmissíveis ${ }^{6}$. Vindo ao encontro dos resultados encontrados através do questionário sobre o uso de cachimbo d'água, 59\% dos usuários fumantes iniciaram o tabagismo aos 13-16 anos, $33 \%$ aos $17-20$ anos e $8 \%$ aos $21-23$ anos. Reafirmando assim, que o primeiro contato com o tabaco tem ocorrido cada vez mais precocemente.

Em uma pesquisa de Martins et al. ${ }^{5}$ aplicada à "estudantes de terceiro e sexto anos de uma faculdade de medicina do estado de São Paulo, foi apontada uma proporção de fumantes de narguilé de 47,32\% e 46,75\% respectivamente", contra $39,1 \%$ obtido no presente trabalho. E ainda com relação ao total de fumantes de narguilé na pesquisa, o achado evidencia um número próximo.

De acordo com Albandar, "acredita-se que atualmente no mundo mais de 100 milhões de pessoas usem narguilé diariamente, sendo mais prevalente que o uso de cigarros em algumas partes do mundo". Cenário comprovado pela análise dos prontuários, com 64\% dos entrevistados fazendo uso somente do narguilé, enquanto o uso do cigarro conta com apenas 5,1\% dos usuários.

Com relação aos dados relacionados ao gênero, $87 \%$ dos usuários são do sexo feminino e $13 \%$ do sexo masculino, sendo que a grande maioria dos entrevistados que participaram da pesquisa, conta com cursos que tem uma maior proporção de mulheres matriculadas. De acordo com o levantamento de dados realizada pelo Ministério da Educação, por meio de análise descritiva, dos "estudantes que frequentam curso superior em instituição privada no Brasil, o percentual de estudantes do gênero feminino (58\%) é superior ao do masculino (42\%)".

Segundo Reveles et al. ${ }^{13}$ "o uso do narguilé permite a socialização, o convívio com amigos e os momentos de descontração", o que deve ser considerado quando analisamos a preferência dos indivíduos mais jovens narguilé, episódio verificado neste estudo. Dos usuários entrevistas, $71,8 \%$ afirmam utilizar a droga quando estão com os amigos, contra 2,6\% que fazem uso quando estão sozinhos.

Além dos malefícios causados pelo uso do narguilé isoladamente, o uso associado é um outro problema enfrentado, sendo um dos motivos da frequência de associação, a facilidade da mistura com outras substâncias. Maconha é a droga mais frequentemente associada (62\%), ficando à frente inclusive da droga lícita mais utilizada entre os jovens, o álcool (13\%).

As percepções errôneas de danos sistêmicos causadas pelo uso de narguilé, deve-se a ausência de orientações e conhecimento acerca das substancias tóxicas encontradas no produto. No presente estudo, 68,5\% dos alunos acreditam que o uso cotidiano do cachimbo d'água não traz malefícios à saúde. Reforçando a ideia de que a ausência de informações caracteriza esse quadro, sendo que $89,75 \%$ dos participantes nunca foram aconselhados a parar de fumar e nem receberam orientações acerca dos malefícios causados pela inalação da fumaça. Em suma, é indiscutível a necessidade da adesão de medidas de saúde que visem a conscientização da população de uma forma geral, incluindo campanhas antitabagistas - assim como o movimento antitabagismo no século passado. Além disso, o papel do médico no processo de orientação sobre os malefícios da droga, bem como uma abordagem mais eficaz quanto aos mitos e realidades sobre essa forma de uso do tabaco, a fim de evitar que fumantes ocasionais se tornem usuários regulares. Medidas de conscientização e conhecimento podem ter o efeito de mudar o comportamento dos futuros médicos, o que poderá refletir na diminuição da prevalência do uso de narguilé e auxiliando nos âmbitos de prevenção e promoção em saúde.

Atualmente, as medidas públicas de enfrentamento 
ao tabagismo atingem uma menor parcela da população quando comparada à década passada. Informações contidas apenas em unidades ambulatórias e hospitalares, restringem as informações referentes a droga, sendo que se o conhecimento fosse dissipado em escolas e em mídias digitais com mais afinco, uma redução de usuários poderia se tornar realidade. Quando abordamos de uma maneira ampla a utilização do narguilé, é extremamente complexo associar doenças desenvolvidas pelo uso dessa "nova" droga, pois não existe um centro que atenda apenas os narguileiros, assim como, em sua grande maioria, os usuários associam o narguilé a outras drogas.

\section{CONCLUSÃO}

Diante dos dados obtidos no estudo, evidenciou-se que a utilização do narguilé entre os estudantes da área da saúde é altamente prevalente e seu uso está alcançando proporções alarmantes. Frente a esse cenário, o estudo também teve como objetivo propor medidas e reforçar ações já existentes, como atuação efetiva da medicina preventiva e campanhas antitabagistas, para que seja possível disseminar informações verídicas acerca do uso do narguilé, a fim de conscientizar e reduzir o número de usuários.

A popularização do narguilé gera preocupações e aponta para a necessidade de se reforçar políticas públicas já existentes, como o aumento dos impostos dos produtos derivados do tabaco e as ações educativas, realizadas pelo Programa Saúde na Escola ${ }^{3}$, voltadas à prevenção e à redução do uso de tabaco. Além disso, é extremamente importante disseminar campanhas, como "Parece inofensivo, mas fumar narguilé é como fumar 100 cigarros", lançada pelo Ministério da Saúde e o Instituto Nacional de Câncer e divulgadas em Unidades Básicas de Saúde, para que a população tenha conhecimento dos reais malefícios causados pelo cachimbo d'água, já que muitos acreditam que o uso da droga não é maléfica. E por fim, é essencial a realização de cursos voltados para os profissionais da área da saúde, para que eles possam e saibam orientar os usuários, além de implementar o desenvolvimento de programas de sensibilização e capacitação dos profissionais de saúde em formação; e assim completar o tripé para alcançamos a eficácia e efetividade das ações em saúde.

Participação dos autores: Michelle Oliveira Paiva: Planejamento da pesquisa, realização da pesquisa, escrita do texto, revisão e reescrita do texto. André Brito de Lima: Realização da pesquisa, criação de gráficos e tabelas. Rogério Saad Vaz: Orientação referente a criação da pesquisa, tradução e revisão de texto. Priscila Granemann: Tradução e revisão de texto.

\section{REFERÊNCIAS}

1. Ribeiro M, Cruz RC. Jovens e o uso do narguilé: a saúde pode ser comprometida? ASSOBRAFIR. 2016;7(1):7-10. http://www.uel.br/revistas/uel/index.php/rebrafis/article/ view/25936.

2. Brasil. Ministério da Saúde. Instituo Nacional do Câncer José Alencar Gomes da Silva (INCA). Controle do tabagismo - Promoção da saúde - SUS [citado 01 jan. 2019]. Disponível em: https://www.inca.gov.br/programanacional-de-controle-do-tabagismo.

3. Brasil. Ministério da Saúde. Instituo Nacional do Câncer José Alencar Gomes da Silva (INCA). Nota técnica: Uso de narguilé: efeitos sobre a saúde, necessidades de pesquisa e ações recomendadas para legisladores. Grupo de Estudos das OMS sobre a Regulação de Produtos de Tabaco (TobReg). Rio de Janeiro: INCA; 2017. Disponível em: https://www.inca.gov.br/sites/ufu.sti.inca.local/files//media/ document//nota-tecnica-uso-de-narguile.pdf.

4. Brasil. Ministério da Saúde. Secretaria de Vigilância em Saúde (SVS). Vigilância de fatores de risco e proteção para doenças crônicas por inquérito telefônico [citado 06 set. 2017]. Disponível em: http://www.saude.gov.br/ noticias/911-indicadores-de-saude/41423-vigilancia-defatores-de-risco-e-protecao-para-doencas-cronicas-porinquerito-telefonico-vigitel-2.

5. Martins SR, Paceli RB, Bucossacos MA, Fernandes FLA,
Prado GF, Lombardi EMS, Filho MT, Santos UP, et al. Experimentação de e conhecimento sobre narguilé entre estudantes de medicina de uma importante universidade do Brasil. J Bras Pneumol. 2014;40(2):102-10. doi: http:// dx.doi.org/10.1590/S1806-37132014000200002.

6. Brasil. UNASUS. Fumaça inalada em narguilé equivale a 100 cigarros ou mais [citado 8 dez. 2014]. Disponível em: https:// www.unasus.gov.br/noticia/fumaca-inalada-em-narguileequivale-100-cigarros-ou-mais $\#: \sim$ :text $=$ Segundo $\% 20$ a\%20Organiza $\%$ C3\%A7\%C3\%A3o\%20Mundial $\% 20$ da,fumar\%20antes $\% 20$ dos $\% 2018 \% 20$ anos.

7. Araujo JA. Perguntas e respostas: narguilé ou cachimbo de água. SOPTERJ. 2016:1-8. Disponível em: http:// www.sopterj.com.br/respirar/images/narguile-perguntasrespostas-sopterj2016-a-araujo.pdf.

8. Lunelli ML, Fernandes MA, Von der Hayde FRF, Azzi VJB. Análise das condições pulmonares de discentes tabagistas de cigarro e tabagistas de narguilé do Centro de Ciências da Saúde da Universidade Regional de Blumenau. ASSOBRAFIR Cien. 2016;7(1):43-57. http://www.uel.br/ revistas/uel/index.php/rebrafis/article/view/22791.

9. Akl EA, Gaddam S, Gunukula SA, Honeine R, Jaoude PA, Irani J. The effects of waterpipe tobacco smoking on health outcomes: a systematic review. Intl J Epidemiol. 2010;39(3) 834-57. doi: https://doi.org/10.1093/ije/dyq002.

10. Roesch SMA. Projetos de estágio e de pesquisa em administração. 3a ed. São Paulo: Atlas; 1999. 
11. Barbetta PA. Estatística aplicada às ciências sociais. 6a ed. São Paulo: Atlas; 2008.

12. WHO Study Group on Tobacco Product Regulation (TobReg). Waterpipe tobacco smoking: health effects, research needs and recommended actions by regulators. Geneva: World Health Organization; 2005. Available from: https://www.who.int/tobacco/global_interaction/tobreg/ Waterpipe\%20recommendation_Final.pdf.

13. Reveles CC, Segri NJ, Botelho C. Factors associated with hookah use initiation among adolescents. J Pediatr. 2013;89(6):583-7. doi: http://dx.doi.org/10.1016/j. jped.2013.08.001

14. Beckert N, Moysés S, Cruz R, Gutoski, L, Scarinci I. Características do uso de produtos derivados do tabaco entre universitários do curso de Odontologia em uma Universidade de Curitiba. Rev Odontol UNESP. 2016;45(1):7-14. doi: http://dx.doi.org/10.1590/18072577.10015

15. Alvur MT, Cinar N, Akduran F, Dede C. Fallacies about water pipe use in Turkish university students-what might be the consequences. Asian Pac J Cancer Prev. 2014;15(5):1977-80. doi: http://dx.doi.org/10.7314/ APJCP.2014.15.5.1977

16. Figueiral VD, Mariano TJ, Berro LC, Carolino IDR, Conegero CI. Conscientização de jovens sobre os riscos do narguilé por meio de material informativo. Arq Mudi. 2015;18:18. http://periodicos.uem.br/ojs/index.php/ ArqMudi/article/view/26970.

17. Jensen PD, Cortes R, Engholm G, Kremers S, Gislum M. Waterpipe use predicts progression to regular cigarette smoking among Danish youth. Subs Use Misuse. 2010;45(7-8):1245-1261. doi: https://doi. org/10.3109/10826081003682909.

18. Menezes AMB. Frequência do uso de narguilé em adultos e sua distribuição conforme características sociodemográficas, moradia urbana ou rural e unidades federativas: Pesquisa Nacional de Saúde (PNS). Rev Bras Epidemiol. 2015;18(2):57-67. doi: http://dx.doi. org/10.1590/1980-5497201500060006.

19. Szklo AS, Sampaio MMA, Fernandes EM, Almeida LM. Perfil de consumo de outros produtos de tabaco fumado entre estudantes de três cidades brasileiras: há motivo de preocupação? Cad Saúde Pública. 2011;27(11):2271-5. doi: http://dx.doi.org/10.1590/S0102-311X2011001100020.

20. Turcoi SRB, Figueiredo VC, Silva VLC. A regulação de aditivos que conferem sabor e aroma aos produtos derivados do tabaco no Brasil. Cad Ibero-Amer Dir Sanit (Brasília). 2014;3(1):44-67. doi: http://dx.doi.org/10.17566/ciads. v3i1.18.

21. Consortium TCL. Regulatory options for hookahs and water pipes - Fact sheet [cited 2014 Mar 30]. Available from: http://publichealthlawcenter.org/sites/default/files/ pdf/tclc-fs-regulatory-options-hookahs2013.pdf.

22. Viegas CAS. Noncigarette forms of tobacco use. J Bras Pneumol. 2008;34(12):1069-73. doi: http://dx.doi. org/10.1590/S1806-37132008001200013.

23. Waked M, Salameh P, Aoun Z. Water-pipe [narguile] smokers in Lebanon: a pilot study. Rev Santé Mediterranée Orientale. 2009;15(2):2-11. doi: http://dx.doi. org/10.26719/2009.15.2.432.

Recebido: 26.10 .2019

Aceito: 10.08 .2020 